\title{
MATERNAL EMPLOYMENT AND CHILD OVERWEIGHT AND OBESITY:LITERATURE REVIEW
}

\author{
Romlah $^{1}$, Anjelina Puspita Sari \\ Midwifery program, faculty of health sciences, Universits Katolik Musi Charitas, South Sumatera, Indonesia
}

\section{INFORMASI ARTIKEL:}

\section{Riwayat Artikel:}

Tanggal diterima: Maret 2020

Tanggal di revisi: Maret 2020

Tanggal di Publikasi: April 2020

Key Word : maternal employment, child excess weight, diseases

\begin{abstract}
A B S T R A C T
Working mothers are suspected of having links with the increase in excess weight (overweight and obesity) in children. Working mothers would be faced with a 'barter' situation of getting the least time spent with their children with the increasing family income. With little time the mothers spend with their children, they might lose control of the intake of food consumed by their children. When children eat more fast food containing high fat and sugar, the children will be more at risk for having excess weight. In fact, excess weight increases the children to suffer from diseases that were once only often suffered by adults. Diseases such as cardiovascular disease and type 2 diabetes mellitus are getting more common in children. Especially for girls, they will experience the process of pregnancy someday. Of course, obesity experienced by them will impact on the pregnancy when they remain obese as adults. Obesity in pregnancy may be at risk of the emergence of gestational diabetes that will allow bearing obese children as well. Therefore, before bad things happen in families with regard to the health of families, parents, especially mothers, should pay attention to the intake of foods consumed by children and devote more time to children in their growth period for Indonesia's better generation.
\end{abstract}

\section{INTRODUCTION}

Parents, especially mothers, are the ones who are most responsible for children's health. One of the most important tasks of mothers is to prepare healthy future generations by paying attention to children's nutritional intake (Case \& Paxson, 2002). Because of the importance of good nutrition for children, mothers are expected to know the health of the food consumed by their children (who, 2002). Good and balanced nutrition intake accompanied by adequate physical activity will be the promotion of good health in the family in shaping children's behavior in combating child overweight and obesity.

Being overweight is a condition of the body with excessive accumulation of body fat and this condition can pose a dangerous risk to body health (WHO, 2002). Especially for overweight and obese children, this condition can determine the quality of health for the next stage of life (Guo \& Chumlea, 1999). Children with excess weight will very likely remain fat when they are teenagers and adults. Overweight children can actually be

*Korespondensi: angelinaps88@gmail.com prevented by the functioning of the role of parents, especially mothers, in controlling the child's nutritional intake to obtain good family health status.

Good family health status is inseparable from family income. With sufficient income, parents can meet the needs of children, including food needs. Therefore, it is not uncommon for mothers to work by leaving the house within a certain time frame to get additional or improved family income. When mothers leave home to work, they are faced with a situation between losing valuable time to give the attention needed by their child and getting material or commodities to meet the needs of the child (Araneo, 2008; Anderson, Butcher, \& Levine, 2003).

Working mothers may be able to provide materials needed by their children. However, with less time spent with their children, especially when their children are eating, these mothers can also lose control of what food their children consume. A study states that working mothers will have an impact on children's dietary intake (Crepinsek \& Burstein, 2004). The study revealed that children with mothers who work full time tend to have a low Healthy Eating Index. The children consume 
more drinks containing soda and french fries and other fast food.

An extremely alarming increase in childhood obesity rates has been reported in several countries (Cawley \& Liu, 2012). Specifically in Indonesia, the results of the National Socio-Economic Survey and Basic Health Research show that the number of overweight children has increased from year to year to year. This situation is certainly something to look out for because the future of the nation's next generation is very dependent on the quality of children, one of which is determined by their nutritional status. Especially for the generation of Indonesian women, health with a balanced or ideal weight status is very important because they will later experience the process of pregnancy, childbirth, and family management, especially children. Therefore, family health by prioritizing children's health is something that cannot be bargained for the better future of Indonesia.

This research was conducted with the aim to determine the relationship of working mothers with obesity in children based on the study of several literary representations (research in America and the UK). The results of this study are expected to be input for working mothers full time in Indonesia to pay more attention to the healthy and balanced nutrition of their children

\section{METHOD}

This was a quasi-experimental study with a The method used in this research was library research (George, 2008). This type of research involves identifying and allocating sources that provide factual information or expert opinion on a research question. Researchers in this library research did not refer to books in the library literally but referred to data in journals obtained online from the internet, given that:

'It is becoming generally accepted that technology builds upon itself and advances quite independently of any link with the scientific frontier' (Allen, 1977)

The quote implies that, in relation to library research that relies on information sources from the internet, researchers could retrieve data from journals that had been uploaded in search engines or internet search engines. Because library research can draw research reports from previous studies (Hasan, 2002), researchers focused the data in this research on studies that had been published online.

The main data for this study was taken from several journals that had examined the relationship between working mothers and child obesity in America and the United Kingdom. These journals were a) The Effect of Maternal Employment on Childhood Obesity in the United States by Araneo b) The connection between maternal employment and childhood obesity: inspecting the mechanisms by Fertig et.al., (2009) c) Maternal Employment and Childhood Obesity: A Search for mechanisms in Time Use Data by Cawley and Liu, (2012) d) The Association of Maternal Employment Status on Nutritional Status among Children in Selected Kindergartens in Selangor, Malaysia by Shuhaimi and Muniandy (2012) and e) Maternal employment and early childhood overweight: findings from the UK Millennium Cohort Study by Hawkins et.al. (2002). In these studies, the criteria for obesity in children were determined by measuring the child's Body Mass Index (BMI) (Center for Disease Control and Prevention, 2015). BMI is obtained from calculations by dividing body weight in kilograms with height squared in meters. According to the CDC growth charts, a child is said to be overweight and obese when the child's BMI is in the percentile range equal to or greater than 85 .

The analysis of this study used descriptive analysis (Surakhmad, 1989) and content 
analysis (Suryabrata, 1983). Descriptive analysis was carried out after collecting data in the form of words in the journals that had been collected which were presented in the form of a description of the contents of these journals (paraphrase of contents). After that, content analysis was carried out according to the content contained in these journals (paraphrase of content developed with the researchers' thoughts adjusted to the research theme).

\section{RESULT AND DISCUSSION}

Of all the journals that were the main reference materials in this library research, working mothers had a significant relationship with obesity in children. Working mothers had a close relationship with the child's diet and food consumed by children.

Araneo concluded that mothers who worked full time with a high education were more likely to have children who were overweight. Fertig et.al and Shuhaimi and Muniandy stated that the working hours needed by working mothers were related to the child's BMI level. The more hours a mother needed to work, the higher the BMI of a child.

For Cawley and Liu's research, working mothers were associated with those who spent less time in child care so this would have an impact on child obesity because children who were not accompanied when eating would consume more calories, especially from fast food such as fried food. Hawkins et.al. and Shuhaimi and Muniandy mentioned that working mothers had a relationship with obesity in children who began in obesity in the first year of the child because working mothers would be faster to provide solid food to their babies.

Overweight in children is caused by many factors. However, this research only focuses on the study of obesity in children associated with full time working mothers. Although some studies suggest that working mothers do not have a significant relationship to obesity in children, researchers in this library research focus on journals that expose a relationship between the two to be a material for reflection for the parties concerned.

\section{Working Mothers and Overweight Children}

From the data collection that researchers have done, changes in work patterns with mothers who take part in full-time work have had significant impacts on obesity in children. These impacts include:

\section{a) Less time to control children's food consumption}

Mothers who have longer hours of work will be more likely to buy fast food and are more likely to reduce the activity of shopping for raw materials to be cooked at home. Mothers who work full time will usually lose valuable time to accompany their growing child to eat together. When mothers can accompany their children, they will have the opportunity to regulate what foods their children will eat, such as giving children food that is not too fatty but highly nutritious. However, if this opportunity is lost, the child will tend to consume the desired food without any control from the family, especially the mother.

Fast food is a very tempting choice for children because the taste is known to be better even though in fact food (including snacks) has been linked to the risk of obesity in children and adults. When the food problem is transferred to the husband, fast food is still a favorite menu that will be given by the husband to their children. Husbands will prefer practicality in buying food rather than busyness that requires time in preparing their own food. Finally, mothers who work full time 
have opened opportunities for their children to eat unhealthy foods.

Unhealthy food can be seen from the amount of fat and lack of fiber. When a child consumes foods that are poor in fiber content, the child's digestion will be disrupted and this condition will cause the body's metabolism to not work properly. Foods that contain lots of fat will also cause excessive fat deposits when calories from carbohydrates and fat are not burned to the maximum, so the child's body will be filled with excess fat deposits. This will trigger obesity that cannot be avoided anymore.

\section{b) Less time to play with children}

Working mothers will also have less time to play with their children. This certainly affects the physical activity that can be done together. Children of working mothers will be more likely to spend time in front of the television or computer playing games because the time playing with these electronic devices is not controlled by their mothers. As a result, these children will have less physical activity so that the burning of calories in their bodies does not occur intensively.

Physical activity of children is very important in burning calories that accumulate in the child's body. If physical activity is reduced or very rarely done, children will tend to be overweight. This will certainly have implications for their health.

Poor physical activity also plays a role in the development of several diseases in children. When the child sits more in front of the TV to watch his favorite shows from the many choices of channels available, the child no longer needs to play in the open yard, but just sit in bed in front of the TV or computer. Sitting continuously for more than three hours in front of a TV or computer screen is no longer something strange for children now. Of course, this will further aggravate the condition of being overweight already possessed by children.

\section{c) The early provision of solid food in addition to breast milk}

Mothers who work full time have limited time off and they must return to work as soon as possible. In fact, babies need exclusive breastfeeding for at least the first six months of life. Consequently, mothers who work full time will provide complementary food before the exclusive breastfeeding period ends.

Providing complementary food that is done early is possible will make the baby have excessive body weight. Obesity that occurs in infants will have an adverse effect on the growth and development of the baby. The obesity will also settle along with the increasing age of the baby. Of course, this can be detrimental to the health of the baby in the future.

\section{d) Handing over of child care to other caregivers}

When mothers who have children decide to work, they tend to hand over the childcare role to other families (grandmothers/aunts) or to others (baby sitters) while the mother works outside the home. Children submitted to other caregivers (baby sitters) will tend to not have strong control in terms of food consumed. When caregivers do not have good knowledge about healthy foods with balanced nutrition, they will be more likely to provide foods that the child likes. This action is done to avoid fussy children who might be difficult for these caregivers.

Caregivers outside the family also have less authority or authority over the child. It is not uncommon for children to have full control over their food and activities. Often, children will choose foods that are more interesting to 
their tastes and activities that are more exciting according to them. When a child eats unhealthy food and carries out minimal physical activity, the child will have a greater chance of getting fat.

\section{Adverse Effects of Obesity on Children}

Obesity in children has a very bad impact on children's health. Several diseases have been reported due to obesity. Obesity (overweight and obesity) can be possible to increase the level of a number of chronic conditions, including cardiovascular disease, hypertension, type 2 diabetes, stroke, certain cancers, muscle and bone disorders, and a number of mental health conditions. In the long term, obesity with several diseases that accompany it can have a negative impact on human life expectancy in the future.

Although many diseases can arise due to obesity in children, the following discussion only focuses on two main diseases that can be caused by obesity in children. These diseases are:

\section{a) Cardiovascular}

Children who are overweight may have high levels of kelosterol, high blood pressure, and abnormal glucose torelance, all of which cause the child to be at risk for cardiovascular disease later in life. Being overweight will clearly manifest manifestation of body fat suppression on the human heart.

Although a child's age may still be in elementary school level, being overweight in children can threaten their heart health. The information we often get is that heart disease is usually associated with the elderly. However, early warning signs are detected in childhood when they are overweight and even many of these children now have high blood pressure as a result of fat accumulation in their bodies. They see warning signals of heart disease in obese children.

\section{b) Diabetes type 2}

Aside from cardiovascular disease which can threaten the health of overweight children, they also risk having high blood pressure, low 'good cholesterol', and high blood sugar, which can result in type 2 diabetes. In recent years, type 2 diabetes mellitus (DM 2) is not only found as an adult disease, but is starting to be found in children. Being overweight is thought to be a cause of increased overweight experienced by children.

Type 2 diabetes mellitus usually occurs after a person over 40 years old. However, this disease is now beginning to appear at an increasingly young age. The symptoms of DM 2 in children are actually the same as DM 2 in adults, which is eating a lot, drinking a lot, and urinating a lot. If an overweight child is often seen going to the bathroom to urinate, including at night, this situation needs to be suspected that the child may have DM. Sometimes, the condition is accompanied by complaints of being tired, weak, and sleepy, and usually after consuming foods that contain lots of sugar they feel fresh and strong again. However, unfortunately these symptoms are often not prominent, and are not realized by the child's parents, so this condition is often considered normal.

Eating patterns that change from consuming traditional foods that are actually healthier to being largely replaced by imported foods from outside, such as fried chiken or fast food fried chicken, pizza, french fries, donuts, and other fast food. Most of these fast foods, which in their home country are known as junk food or junk food, have very high calorie content because they contain a lot of sugar, processed carbohydrates, and fats. But in fact, these foods become a favorite food for most children 
now. Canned drinks that contain very sweet soda often complement the children's food now. So, obesity due to eating unhealthy foods is a risk factor for children to suffer from type 2 diabetes earlier.

DM 2 that develops at the age of this child can result in a greater risk of complications, such as kidney failure, blindness, neurological disorders, heart problems, or leg amputations. Moreover, drug treatment such as metformin, insulin in children is still doubtful effectiveness. Patients with type $2 \mathrm{DM}$ in children, whose blood sugar is difficult to control properly, will increase the risk of early DM complications. No wonder later, at the age of 30-40 years they have had to experience amputation of the legs, blindness, kidney failure and so on.

With more and more diseases that can be suffered by children due to obesity they experience, parents have a very important role to change the diet for children who are already overweight and provide healthy food to achieve good health status of children.

Especially for girls' health status, parents should pay more attention to their health because they will later experience the process of conceiving, giving birth and caring for children. When they are overweight when they are very young, they are likely to remain fat after they reach adulthood.

The impact of obesity itself will continue when they become adults and, for example, contain. Gestational diabetes or diabetes in pregnancy may occur and as a result the prospective mothers will have babies who are overweight too. Circumstances like this should have been realized by every parent, especially the mother, to avoid having unhealthy offspring. Family health must be a priority with children's health being made a vigilance to create a better generation.
Understanding obesity in children is important to formulate steps that need to be taken for the family to create a healthy family. The most important steps are to increase the awareness and awareness of parents about the relationship between food consumption decisions consumed by their children and the health outcomes (or risk factors) that their children will experience.

Because obesity in children in this literature review is related to mothers who are full-time workers, mothers must be aware of the consequences of a tradeoff (barter) of less time to spend with their children with more income. The decision to create a healthy family is in the hands of both parents, both husband and wife. However, when both parents decide to work, they must be prepared for the consequences they might have that have an impact on their family's health status.

\section{CONCLUSION}

Working mothers will probably have a risk to their child's condition. the more time it takes for mothers to work outside the home will impact on the less time spent meeting their children. Quality time, such as accompanying a child while eating, may be lost and mothers will lose a good opportunity to directly control the intake of food consumed by their child.

The lack of control given by parents, especially mothers, on the food consumed by children is likely to cause children to suffer from being overweight. This is because children consume more foods that contain high fat and sugar. Obesity in children can actually have an impact on the emergence of diseases that used to be only usually suffered by adults.

When children suffer from diseases due to their obesity, a healthy family is certainly not achieved. Therefore, every parent, especially mothers, is advised to always monitor the intake of food consumed by children to avoid 
obesity or overweight in children. A healthy family will create a healthy country as well, and the role of mothers to prepare for a healthy generation is inevitable.

Midwives as partners of women not only provide counseling during pregnancy but they are also expected to be able to provide health counseling to regulate obesity in children on leaflet sheets that they make so that the sheet will continue to be remembered by working mothers. Therefore, midwives can be more creative in making leaflets that are useful for the next phase of women's lives after pregnancy and childbirth, namely the parenting phase to provide physical and spiritual welfare to their children.

\section{Special Interests}

This research will soon be followed up with a Qualitative-Interview study to dig deeper into the opinions or opinions of working full-time mothers towards obesity experienced by their children. The results of this study are expected to be the basis for further research.

\section{REFERENCE}

Case, A., and Paxson, C. (2002). Parental Behavior and Child Health. Journal of Family \& Envoronment.

The WHO. (2015). Global Strategy on Diet, Physical Activity, and Health.

Guo SS, Chumlea WC. (1999). Tracking of body mass index in children in relation to overweight in adulthood. American Journal of Clinical Nutrition.

Araneo, J. (2008). The Effects of Maternal Employment on Childhood Obesity in the United States.

Anderson PM, Butcher KF, Levine PB. (2003). Maternal employment and overweight children. J Health Econ.
Crepinsek M, Burstein N. (2004). Maternal employment and children's nutrition. Electronic Publications from the Food Assistance \& Nutrition Research Program. US Department of Agriculture/Economic Research Service, Washington, DC.

Cawley, J., and Liu, F. (2012). Maternal employment and childhood obesity: A search for mechanisms in time use data. Economics and Human Biology.

George, M., W. (2008). The Elements of the Library Research. Princeton University Press.

Allen, Thomas J. (1977). Managinng the Flow of Technology: Technology Transfer and the Dissemination of Terhnological Information within the Research and Development Organization. Cambridge, Mass.: MIT.

Hasan, M. I. (2002). Pokok-pokok Materi Metodologi Penelitian dan Aplikasinya. Ghalia. Indonesia, Bogor.

Fertig, et. al. (2009). The Connection between Maternal Employment and Childhood Obesity. Springer Science+Business Media, LLC.

Shuhaimi, F. \& Muniandy, N. D. (2012). The Association of Maternal Employment Status on Nutritional Status among Children in Selected Kindergartens in Selangor, Malaysia. Asian Journal of Clinical Nutrition.

Hawkins, et. al. (2002). Maternal Employment and Early Childhood Overweight: Findings from the UK Millennium Cohort Study. Centre for Paediatric Epidemiology and Biostatistics, Institute of Child Health, 30 Guilford Street, London WC1N 1EH, UK.

Center for Disease Control and Prevention. (2015). Division of Nutrition, Physical Activity, and Obesity. U.S Department of Health \& Human Services.

Surakhmad, W. (1989). Pengantar Penelitian Ilmiah Dasar dan Teknik. Bandung: Tarsito.

Suryabrata, S. (1983). Metodologi Penelitian. Jakarta: CV. Rajawali. 